\title{
Infatuation, Romantic Relationship and Learning Behaviour among School Going Adolescents
}

\author{
Gururaj Ganapati Gouda ${ }^{*}$, \& Laveena D'Mello \\ $1 *$ Research Scholar, Shrinivas University, Mangalore, Karnataka, India. \\ OrcidID: 0000-0001-9339-5862; Email: gururajitgi@gmail.com \\ ${ }^{2}$ Associate Professor, College of Social Sciences \& Humanities, Srinivas University, \\ Mangalore, Karnataka, India. \\ OrcidID: 0000-0003-1935-002X; Email: lavynoronha@gmail.com
}

Area/Section: Social Science.

Type of the Paper: Research Paper.

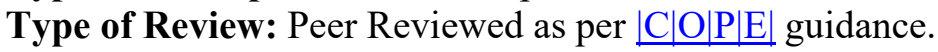

Indexed in: OpenAIRE.

DOI: http://doi.org/10.5281/zenodo.4554589.

Google Scholar Citation: IJMTS.

\section{How to Cite this Paper:}

Gururaj Ganapati Gouda \& D’Mello, Laveena, (2021). Infatuation, Romantic Relationship and Learning Behaviour among School Going Adolescents. International Journal of Management, Technology, and Social Sciences (IJMTS), 6(1), 71-82. DOI: http://doi.org/10.5281/zenodo.4554589.

International Journal of Management, Technology, and Social Sciences (IJMTS)

A Refereed International Journal of Srinivas University, India.

(C) With Author.

CrossRef DOI: https://doi.org/10.47992/IJMTS.2581.6012.0130

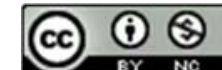

This work is licensed under a Creative Commons Attribution-Non-Commercial 4.0 International License subject to proper citation to the publication source of the work.

Disclaimer: The scholarly papers as reviewed and published by the Srinivas Publications (S.P.), India are the views and opinions of their respective authors and are not the views or opinions of the SP. The SP disclaims of any harm or loss caused due to the published content to any party.
\end{abstract}




\title{
Infatuation, Romantic Relationship and Learning Behaviour among School Going Adolescents
}

\author{
Gururaj Ganapati Gouda $^{1^{*}}$, \& Laveena D'Mello ${ }^{2}$ \\ $1 *$ Research Scholar, Shrinivas University, Mangalore, Karnataka, India. \\ OrcidID: 0000-0001-9339-5862; Email: gururajitgi@gmail.com \\ ${ }^{2}$ Associate Professor, College of Social Sciences \& Humanities, Srinivas University, \\ Mangalore, Karnataka, India. \\ OrcidID: 0000-0003-1935-002X; Email: lavynoronha@gmail.com
}

\begin{abstract}
The adolescence is an important period in which one's character, behaviour, habits, and future lifestyles are developed. Influence of peer is more than the influence of adults, parents, and teachers in this period. Therefore, this research paper aims to explore the potential impact of infatuation and romantic relation to learning behaviour of school-going adolescents. Total of 108 adolescent students were surveyed using the questionnaire method. Both the primary and secondary data are used in this study and it is descriptive in nature. Result highlights that a majority of the respondents have experienced distraction, stress, and low academic performance due to infatuation and romantic relationship. It has a negative impact on learning behaviour among adolescents undergoing infatuation or romantic relation. It is recommended that creation of awareness among teachers and parents in the school and home to provide appropriate support and care to the adolescents is essential. A flexible environment in the school and home must be created to make the adolescents develop positive behaviour towards learning.
\end{abstract}

Keywords: Infatuation, Romantic Relationship, Learning Behaviour, Adolescents, and Academic Performance.

\section{INTRODUCTION :}

India is the most adolescent populated country in the world and it consists of 243 million individuals aged 10-19 years. Around 20 percent in its population are adolescents [1]. The teenage or adolescent period is an important period in everyone's life. In adolescent period, children get developed character, habits and future lifestyles. It is also a period in which the influence of the peer group is more than the influence of adults, parents or teachers [2]. Teenagers like to withdraw themselves from dependency on parents. Further, this period is also characterized by physical and emotional related behaviours like attraction towards the opposite sex. When a child enters the adolescent period, it will experience hormonal variations in its physical and psychological change. The child will start to seek a social identity and a special consideration in society on the basis of gender [3]. This age also influences the teenager to be more conscious about their physical appearance, such as dressing, beauty and making them attractive. Also due to the production of sexual hormones in their body, they naturally attract their peers who belong to the opposite sex. Even though it is the normal process, teenagers consider such attraction as love.

Adolescents are highly passionate in such a relationship, which will also result in several psychological problems in their day-to-day living [4] [5]. Parent's rejection of romantic relationship makes adolescents become desperate. Even some of them never disclose their relationship with a romantic partner thinking that it will not be approved by their parents. Sometimes they are helpless even though they knew the negative impact of their relationship on their academic performance. Janardhana, \& Manjula (2018) found that many adolescents believe that sexual intercourse with their partners is a method to get marriage approval from their parents [6]. They get influenced from the multiple corners of society, such as social media, peers and family. Modernized parenting and influence by the external world are causing adolescents to withdraw themselves from the family. In such situations, adolescents think that they can 
making independent decisions about their physical and mental health. At the same time most adolescents experience significant challenges that can disturb physical, emotional, and educational wellbeing. Among these, high-risk behaviours such as romantic relationship and sexual behaviours can lead to scholastic backwardness [7]. Addressing this issue is an essential responsibility for the social concern to promote a healthy and positive living of the young population. Family, schools, community and other responsible stakeholders should consider the behavioural response of adolescents towards infatuation and its impact on their scholastic performance [8]. Educating them to play a better role in the family and society, enabling them to develop a heavy and positive peer relationship, creating a sense of responsibility towards the academic achievement for a better life are the areas to promote a positive and safe living experience. A positive experience in the early life experience will promote good characteristic and maturation in adulthood [9] [10].

\section{DEVELOPMENT, INFATUATION AND ROMANTIC RELATIONSHIP :}

Physical and psychological development in the adolescent period is the determinant for the pattern of behaviour and set of characteristics that they adopt. These characteristics and patterns of behaviour play a major role in deciding how an adolescent understand and react for infatuation. Even the society and peer group influence will also promote a positive attitude towards the opposite sex in the adolescent period.

\subsection{Physical Development:}

The most important and noticeable change during physical development is sexual growth, including the appearance of secondary sexual characteristics and the ability to reproduce. Teenagers with these physical changes will mainly get attracted by the opposite sex. Physical changes are uncommon in all levels of the adolescent period [11]. Though, sexual growth among young adolescents triggers for their romantic relationships with the opposite sex and affect relationships pattern with family members. Continues engagement in such a relationship also causes negative developmental and unhealthy academic life. Their immaturity will push them into several physical and mental problems. Mental stress affects their academic life and social activities [12].

\subsection{Psycho-Social Development:}

The peer group plays a major role in adolescent's psycho-social development. They contribute more to the emotional changes and the relationship pattern that adolescents adopt in their day-to-day life. Therefore, adolescents seek peers who are more similar to their thoughts and emotions. These peer group push adolescents into several risks [2]. Thus, adolescents face challenges to balance peer pressure and family expectations. In such situations, adolescents think that they can make independent decisions in their personal and social life. They start seeking a supportive relationship with the opposite sex and stop giving importance to their own family. They also think that they can have more comfort by developing a romantic relationship with the opposite sex. They are not fully potential to understand the emotional and physical needs in the process of psycho-social development. This immaturity will trigger their attention towards love relationship through which they try satisfying their developmental needs. The behaviour of Infatuation or sexual experimentation risks their autonomy and creates several challenges to balance their emotional stability. This type of behaviour will also lead to various mental health problems triggering learning-related distractions [13].

\subsection{Cognitive Development:}

Changes in cognitive development among adolescents are highly influential to decide their level of perception and behavioural reactions towards life situations. During this period, adolescents begin to mature and start thinking independently for their future life. Adolescents with these thinking are prone to select their romantic partner to have a comfortable experience in their present life. Their limited cognitive capacity to comprehend and analyze any situations or find appropriate solutions will maximize the complexity of simple problems. These issues will result in several mental health challenges even negatively affect the relationship with the peer group, family and romantic partner [14] [15]. 


\section{INFATUATION AND SCHOLASTIC PERFORMANCE :}

Von Stumm et al., (2011) found in their study that when a human mind is hungry it will try finding the source of knowledge and will have the best performance in academic [16]. Adolescence is a time to adopt verity of new behaviours from society without appropriate maturity or knowledge. They tend to the experimentation in each step of their development, which will also increase risk in their life. Since adolescence is a time of learning their behavioural pattern play an eminent role to decide their academic performance and learning involvement. Adolescents underestimate the consequences of such behaviours (for example, infatuation towards opposite sex). The focus of adolescents towards a romantic relationship with the opposite sex will directly or indirectly affects their learning aspects. Adolescents neglected by both the family and by educational professionals will likely to experience several psycho-social problems such as stress, depression, anxiety, inferiority, isolation, which leads to scholastic backwardness [17]. Schmidt and Lockwood (2017) identified a significant relationship between romantic relationship and class absence among the students. This result indicates how students are failures to attend classes regularly and show low performance in their academics [18].

\subsection{Role of family:}

A family is also responsible for adolescent's academic performance. Several family-related problems such as separation or divorce, parental illiteracy, substance use disorder among parents, poverty, family fitting, or any physical or mental problems among family members are the causes that influence adolescents to stop seeking a comfortable life in their family. In this situation, they engage themselves in a romantic relationship to fulfill their desire for happiness. Anxiety disorder or childhood depression among adolescents which is interlinked with family issues also cause scholastic backwardness [19]. The modernized family life lessens the amount of time and space for communication that family members make for their children. Decreased support systems and appropriate supervision from caretakers are also a challenge to provide a good platform to the adolescents to promote their well-being. Adolescents are missing an important aspect of family care and love. People are busier with machinery rather than engaging themselves with human beings. This behaviour will also have a negative impact on an adolescent's academic performance. Savioja (2019) found a lack of parental involvement in adolescent's living is a cause for risk-taking sexual behaviour among them. Therefore, appropriate parental care and support, active involvement of the parents in the daily living of adolescents will help them adopt good behaviour and stay protected from the negative effect of infatuation [20].

\subsection{Role of Peers:}

The motivation for a romantic relationship mainly comes from peers. Adolescents tend to have membership in peer groups, which will also promote infatuation towards the opposite sex. Most of the time peer group is a promoter of an unhealthy relationship with the opposite sex, which will negatively impact academic achievement. This behaviour will also increase the depression among adolescents and reduce their academic outcome. It will also motivate adolescents to withdraw from family and get involved in unhealthy social activities [21]. Increased use of cell phones among adolescents is also a key indicator of the tendency to be curious about a romantic relationship with the opposite sex [2].

\subsection{Role of Community:}

The adolescent period is an appropriate period for better socialization. If adolescents are capable of creating social acceptance through their good behaviour, it helps them succeed their professional as well as personal life. However, while living in this society adolescents should be careful to deal with various consequences, which end their life. Bothe people and the social situation around the adolescents are highly influencing their overall development [22]. Adolescents are curious to observe and adopt social behaviour, which will attract their concentration. That be a media, people in society or any incidents related to romantic relationships, love or infatuation around adolescents are grabbing their attention. When adolescents are not aware and valued within the community and its principles, they are easily influenced to commit a mistake [23]. 


\subsection{Role of Teachers:}

High expectation than the actual ability of the students, negative feedback, over control, not being able to understand student's feelings and the imbalanced relationship between teachers and students are the key indicators to the adolescents to be distracted from studies and get influenced of negative social behaviour. In such a situation adolescent even seek a supportive and comfortable relationship from the opposite sex, which will also negatively affect their academic performance. The lack of teacher's attention towards understanding changing behaviour and imbalanced emotions of adolescents is an area to provoke adolescents to be isolated from the home and school or from the adults [24] [25].

\section{INFATUATION \& ROMANTIC RELATIONSHIP :}

Infatuation is a strong romantic feeling in the state of unreasoned behaviour or passion towards the opposite sex. Infatuation surprisingly occurs and it becomes too deep and more influential over time, but it is just for a short time. Irrespective of family, ethnicity, geographical background both boys and girls tend to be curious and attentive towards cross-sex friendship or romantic relationship [26]. Adolescents with infatuation feel only the positive side of their partners. Adolescents with infatuation are more focused on the physical aspects of the partner rather than their overall good. They also adopt jealousy and possessiveness and they neglect other relationships, especially with parents, teachers and other caretaking adults. The adolescents with infatuation will be selfish and most of the time being rude to others [27]. These types of infatuation have an unhealthy outcome in adolescent's day-to-day living. Adolescents are much into infatuation separate themselves from supportive friendship networks. Sometimes even they express violent behaviour within their romantic relationship. Social media is playing a major role between adolescent's romantic relationships. Aggression in such a relationship leads to several problems like school dropout, being absent to the class, lack of concentration, negative attitude towards learning, fail to meet the learning requirements, etc. [28] [29]. The misinterpretation of infatuation as love is one of the major causes for problematic acting-out behaviours, such as selfharm, depression, low self-esteem, feelings of helpless, hopeless and worthless [30].

Janardhana and Manjula (2018) found that adolescent girls thinking that having sexual intercourse with their romantic partner is a method to get parent's approval for marriage. They also noted a romantic relationship leading to school dropout and academic failure among adolescents [31]. Most adolescents with infatuation tend to watch online pornography [32]. This behavour leads to teenage pregnancy, sexual abuse, problems in the relationship with family, friends and teachers, or any mental health problems. Adolescents addicting to online pornography watching show a lack of interest in learning. Miranda et al., (2019) identified that a romantic relationship affects Attention Deficit Hyperactivity Disorder (ADHD) among adolescents [33]. Too much infatuation or feeling about the romantic relationship will be negatively affected on adolescent's day-to-day living behaviour. [34]. A relationship breakup is commonly found among adolescents irrespective of male and female. Even most adolescents in the above group were been identified with several mental health problems such as selfharm and suicide [35]. Herrera et al., (2006) found that breakup in a romantic relationship is also an important cause for suicide. This study highlighted effects of teenage infatuation on adolescent's mental health \& learning behaviour [36].

\section{OBJECTIVES :}

The study is intended to identify the impact of infatuation on learning behaviour of school-going adolescents. Therefore, the first objective of the study is to identify the status of infatuation among adolescents. The second objective is to understand the behavioural response of adolescents towards learning. Finally, the study is to find the impact of infatuation on learning behaviour of the adolescents and recommend for the needful caregiving and education for different stakeholders.

\section{METHOD :}

The study is descriptive in nature. A total of 108 students were randomly selected from one of the educational institutions in Mangaluru district, Karnataka, India. In this selected sample 79.62 percent (86) were male and 20.37 percent (22) were female included. The samples were adolescents aged between 13 years to 18 years studying in VIII, IX, X, XI and XII classes. Researcher developed questionnaire to determine the status of infatuation, external influence for infatuation and learning 
behaviour of adolescents. The questionnaire was constructed under three categories, which included ten questions each. The researcher validated the developed questionnaire by three subject experts. Both Interview and questionnaire method were used for data collection.

\section{RESULT :}

\subsection{Personal Data:}

A number of respondents taken for the study are 108. Male respondents were $86(79 \%)$ and female were $22(20 \%)$ in which forty-two respondents aged between 12 and 14 years, 40 respondents between 14 and 16 years and 26 respondents between 16 and 18 years. Education wise distribution of the sample is $26(24 \%)$ from class VIII, 34 (31\%) from class IX, 20 (18\%) from class X, $10(9 \%)$ from class XI, and $18(16 \%)$ respondents from class XII. Locality wise distribution is $92(85 \%)$ of the respondents belonging to an urban area and $16(14 \%)$ respondents belong to a rural area.

\subsection{Family Data:}

Family wise distribution is, $98(90 \%)$ respondent's family is nuclear families and $10(9 \%)$ families are joint families. 48 (44\%) respondent's fathers are degree and above educated, $36(33 \%)$ respondent's fathers are above tenth and above educated and $24(22 \%)$ respondent's fathers are below tenth educated. $32(29 \%)$ respondent's fathers are private employees, 52 (48) are doing business $16(14 \%)$ are government job holders and $8(7 \%)$ have no job. 64 (59\%) respondent's mothers are degree and above educated, $36(33 \%)$ respondent's mothers are above the tenth and above educated and $8(7 \%)$ respondent's mothers are below tenth educated. $20(18 \%)$ respondent's mothers are private employees, $56(51 \%)$ are home maker $20(18 \%)$ are government job holders and $16(14 \%)$ are doing their own business. No respondent's family income is below 20000, 12 (11\%) respondents family income is above 20000 and below 50000, 20 (18\%) respondents family income is above 50000 and below one lack and $76(70 \%)$ respondent's family income is more than one lack.

\subsection{Status of Infatuation:}

$40 \%$ male and $48 \%$ female know the difference between love and infatuation. $46 \%$ male and $38 \%$ female respondents reported that they have experienced romantic feelings. $32 \%$ of male and $24 \%$ of female respondents have experienced romantic relationship with the opposite sex.

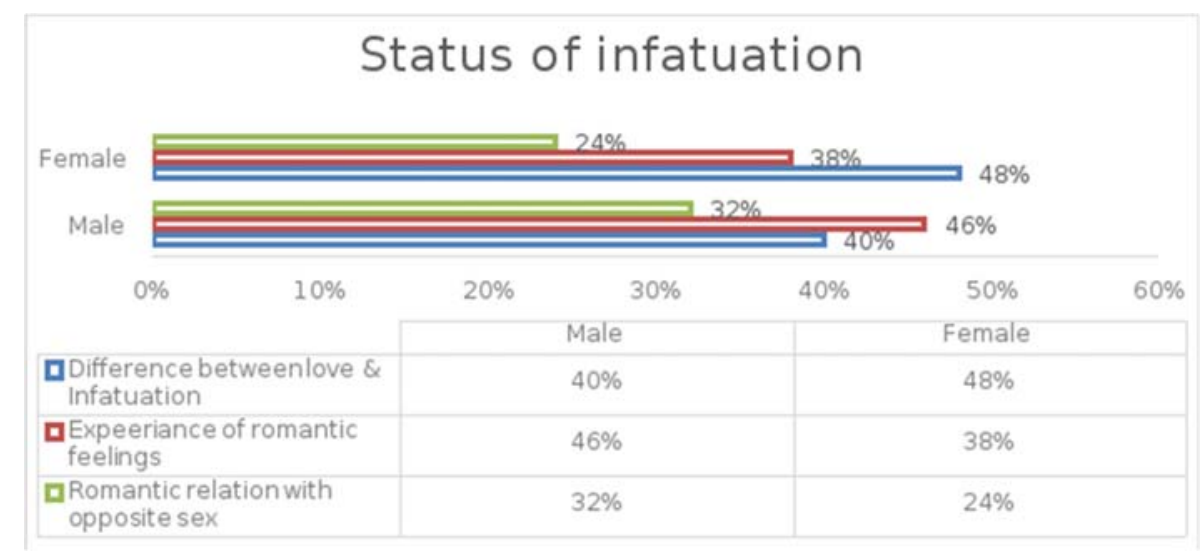

Fig. 1: Status of infatuation \& romantic relationship.

$68 \%$ male and $82 \%$ female respondents reported that they have fear on parents and teachers to have a romantic relationship. $32 \%$ male and $30 \%$ female have still continued their relationship with their romantic partners. $30 \%$ male and $38 \%$ female respondents reported that they dropped out of a romantic relationship. 56\% male and $74 \%$ female respondents are aware of the negative impact of infatuation or romantic relationships on their academic performance. 


\section{Status of infatuation}

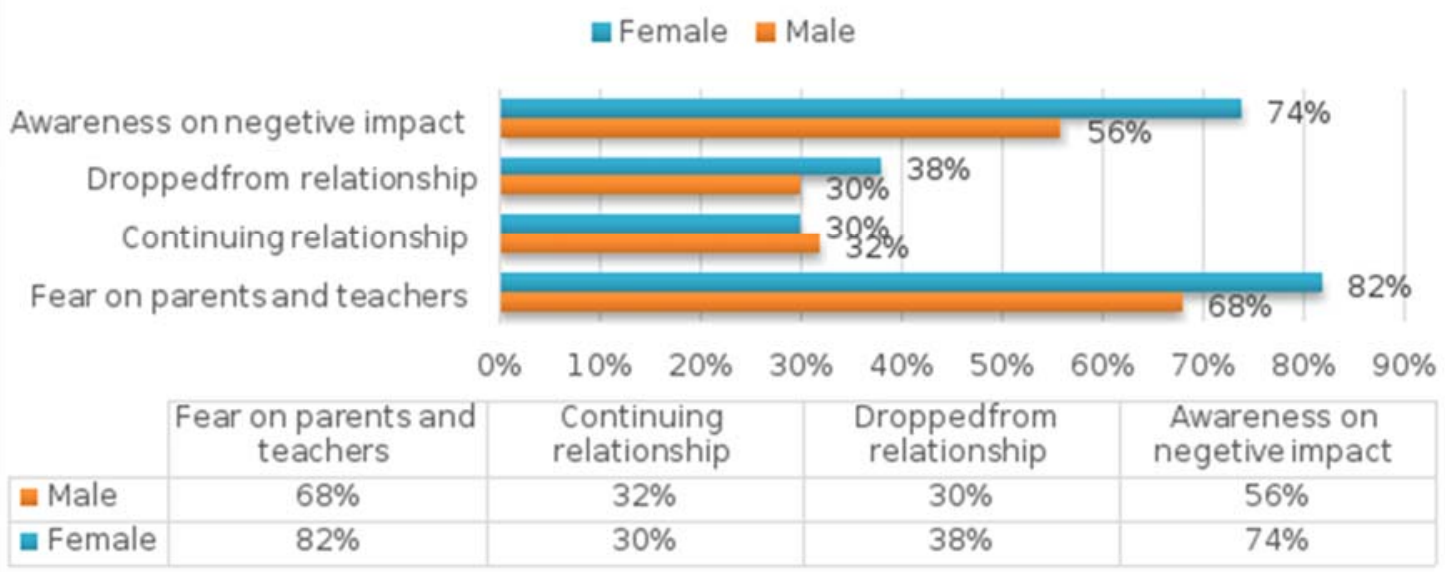

Fig. 2: Status of Infatuation \& romantic relationship.

\subsection{Role of the Peer Group, Social Media \& Society:}

The report of the data collected from the samples indicates that $44 \%$ male and $28 \%$ female respondents often fall into the distraction by the peer influence towards opposite-sex attraction. $74 \%$ male and $42 \%$ female respondents reported that they discuss infatuation or romantic relationship with their peers. $74 \%$ male and $68 \%$ female respondents said the peer group is the most influential group towards infatuation or romantic relationship. $48 \%$ male and $40 \%$ female respondents said social media is also the highest influencing towards infatuation or romantic relationship. $18 \%$ male and $16 \%$ female respondents reported neighbourhood and family have an influence towards infatuation or romantic relationships.

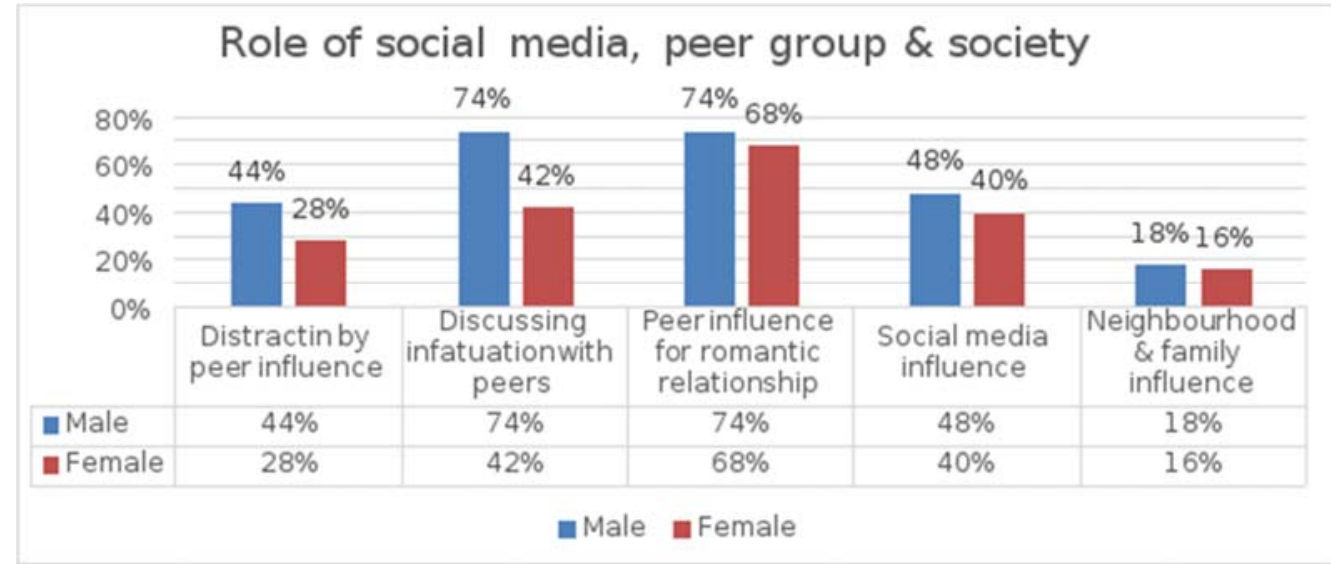

Fig. 3: Role of social media, peer group \& society.

\subsection{Infatuation and Learning Behaviour:}

$52 \%$ male and 74 female respondents reported that they are aware of the negative impact of infatuation and romantic relationship on academic their performance. $18 \%$ females and $36 \%$ male respondents reported that currently their learning is distracted by infatuation or romantic relationships. $48 \%$ male and $26 \%$ female have past experience of getting distracted in their learning due to infatuation or romantic relationships. 58\% male and $44 \%$ female said they felt bored to attend class when they are in a romantic relationship. $52 \%$ male and $48 \%$ female reported that they lost learning interest due to infatuation or romantic relationships. 


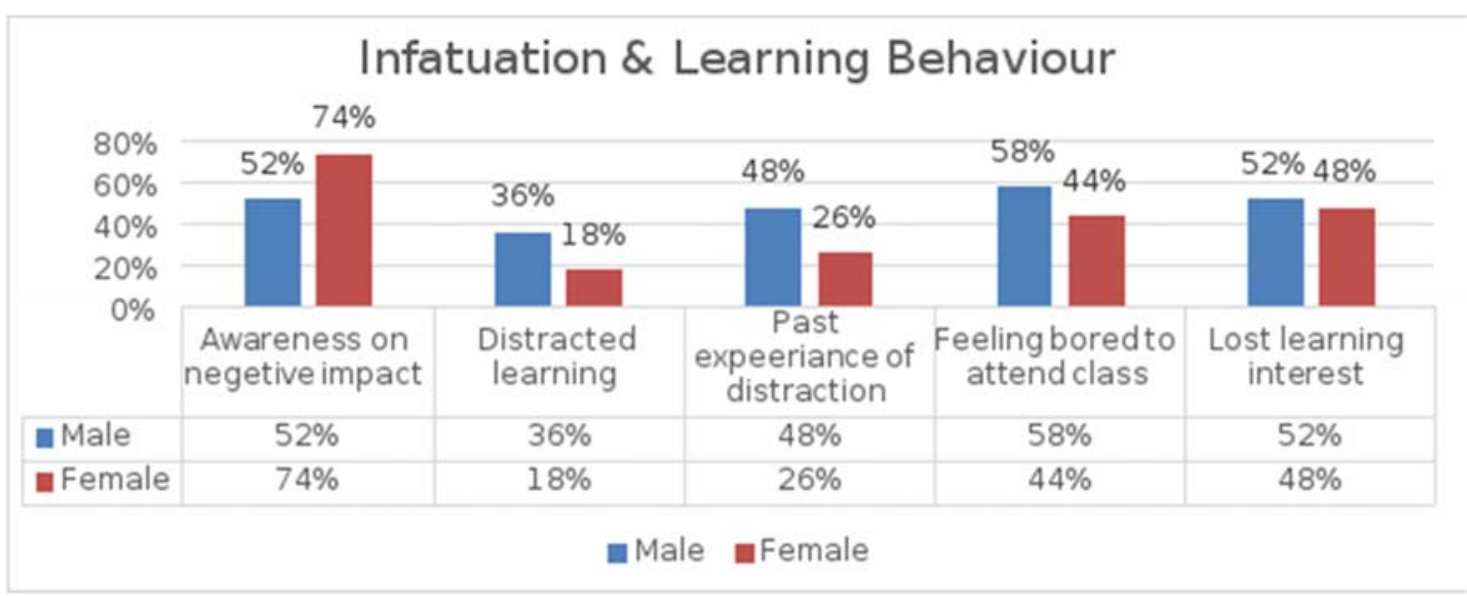

Fig. 4: Infatuation \& learning behaviour.

$12 \%$ females and $20 \%$ male reported that they sometimes used to skip from the class due to infatuation or romantic relationships. $44 \%$ of male and $26 \%$ of female respondents are low in their academic performance. $36 \%$ male and $38 \%$ female respondents reported that they have experienced stress due to infatuation or romantic relationships. $14 \%$ female respondents sometimes they report teachers or family members about their problems related to infatuation or romantic relationship. However, no male respondents report to teachers or family members about their problems related to infatuation or romantic relationship.

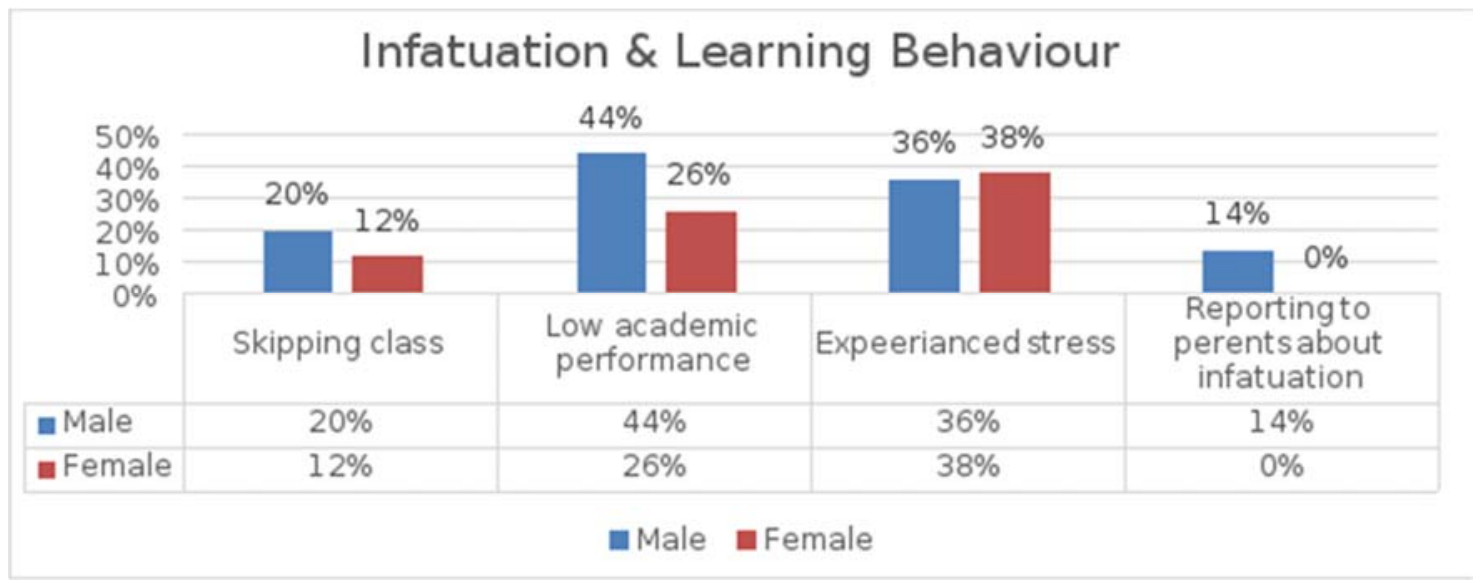

Fig. 5: Infatuation \& learning behaviour.

\section{DISCUSSION :}

The study explored the impact of infatuation on learning behaviour of school-going adolescents. Obtained data revealed that around half of the respondents aware of differences between love and infatuation, which mean more than fifty per cent of the respondents not aware of these differences. This result shows how the adolescents are lacking appropriate education and awareness about love and romantic relationship. The study also identified most of the male respondents experienced romantic feelings than female respondents. Even in experiencing a romantic relationship with opposite sex male respondents are higher than female respondents [37]. However, male children have a special concern in Indian society and they also enjoy all freedom compare to female children. This concern towards male children may be by the fear among female children on parents and teachers to have a romantic relationship compare to boys. Around thirty per cent of male and female respondents are currently in a romantic relationship with opposite sex same per cent of male and female respondents dropped from such relation. However, the significant majority of the female respondents compared to male respondents are aware that the infatuation or romantic relationship has a negative impact on their academic performance [38]. 
The data obtained in this study are also indicating that the majority of the male respondents reported that peer group influence towards opposite-sex attraction. They also discuss a romantic relationship with their friends. Since adolescent age is a time for independence and these children spend more time outside and in school with their friends rather than with parents in the home, most female respondents to agree that peer group is the most influencing group towards infatuation or romantic relationship [2]. Male and female respondents equally accepted that even social media has highest influenced towards infatuation or romantic relationship. Excessive availability of digital technologies such as mobile and computers are the major reason behind social media effect on infatuation [39]. Compare to male respondents female respondents are highly aware of the negative impact of infatuation and romantic relationship on academic their performance. Most male respondents are currently under learning distraction by infatuation or romantic relationship. The majority of male respondents compare to female respondents reported that they have past experience of getting distracted in their learning due to infatuation or romantic relationship. Male and female respondents are almost equally felt bored to attend class and they lost learning interest due to infatuation or romantic relationship.

Most male respondents are performing low in their academics compare to female respondents. However, both male and female respondents are equally reported that they have experienced stress due to infatuation or romantic relationship [37]. Less majority of the female respondents sometimes report to teachers or family members about their problems related to infatuation or romantic relationship. However, no male respondents report to teachers or family members about their problems related to infatuation or romantic relationship. Parents should maintain continues attention towards their children's daily activities and behaviour. Adolescents will become healthy adults if their family remains actively take part in providing good parenting, love and care throughout the process of developing maturity. Parents can actively involve when they well educated on the physical, cognitive, social, and emotional changes that occur during adolescence. If the parents pay their attention towards adolescent's issues by providing timely support, increasingly they perform in their academics. To develop academic partnerships between educational institutions and family, the educational professional can consider the parents as ethical and behavioural models for their children. They also can encourage parents to communicate with their children to understand their expectations properly and respectfully. Although adolescence is specially considered for growing independence and separation from parental control, the adolescent still needs the family's care, love, support, and availability, where they can live away from several physicals, emotional, and social problems and involve actively in their day to day learning. [40]

Adolescents need family members, educators, health professionals, and counsellors to solve their problems. They should help adolescents through their active listening, respecting their confidentiality and responding immediately to their problems. Mental and physical healthcare professionals need to develop innovative approaches to effectively engage adolescents in process of caring and nurturing. Using positive peer influence is an effective method for adolescent academic enhancement. A good supervision plays an important role in strengthening the partnership between the educational professionals, family, and adolescents in major ways: providing them accurate information about adolescent's social, emotional and academic issues. Encouraging and trying to develop positive habits in adolescents and recognizing their unique qualities. Therefore, parents must be educated and students in the schools and colleges must be created awareness about the infatuation and romantic relationship. Parents should take initiative to encourage their children to express their feelings [41][42]. Mental health assistance to be provided in each school through which children can find solutions for problems related infatuation or romantic relationship. Even teacher student's relationship should be well maintained to keep students encouraged to take their help to understand the infatuation [43].

\section{CONCLUSION :}

Our study highlights that most respondents have experienced distraction, stress and low academic performance due to infatuation and romantic relationship. The study also shows a negative learning behaviour been expressed by adolescents in infatuation or romantic relations. It is recommended to create awareness among teachers and parents in the school and home to provide appropriate support and care to the adolescents. Different programs to be planned to strengthen adolescents in their capacity to cope with challenges. Help adolescents be capable to manage the distraction and improve their academic performance. A flexible environment in the school and home to be created to make the 
adolescents develop positive behaviour towards learning. The study also suggested for the further investigation on the related areas on the large group of adolescents to explore further possibilities of impacts of infatuation and romantic relation on learning behaviour.

\section{REFERENCES :}

[1] National Commission on Population (2019, November). Population Projections for India and States 2011 - 2036. Ministry of Health \& Family Welfare. https://nhm.gov.in/New Updates_2018/Report Population_Projection 2019.pdf

[2] Berten, H. \& Van Rossem, R. (2011). Mechanisms of peer influence among adolescents: Cohesion versus structural equivalence. Sociological Perspectives, 54(2), 183-204.

[3] Berlan, E. D., Corliss, H. L., Field, A. E., Goodman, E. \& Austin, S. B. (2010). Sexual orientation and bullying among adolescents in the growing up today study. Journal of Adolescent Health, 46(4), 366-371.

[4] Hatfield, E., Brinton, C., \& Cornelius, J. (1989). Passionate love and anxiety in young adolescents. Motivation and Emotion, 13(4), 271-289.

[5] Connolly, J., Craig, W., Goldberg, A. \& Pepler, D. (1999). Conceptions of cross-sex friendships and romantic relationships in early adolescence. Journal of youth and adolescence, 28(4), 481-494.

[6] Janardhana, N., \& Manjula, B. (2018). Infatuation and love of an adolescent girl: Dynamics of parent child relationship. Indian Journal of Child Health, 5(2), 99-103.

[7] Cohen, G. L., \& Prinstein, M. J. (2006). Peer contagion of aggression and health risk behavior among adolescent males: An experimental investigation of effects on public conduct and private attitudes. Child development, 77(4), 967-983.

[8] Basavaraju, M., \& Navaneetham, J. (2019). Beyond infatuation and love: Review of adolescent mental health manuals in India. Archives of Mental Health, 20(1), 3-8.

[9] Christie, D., \& Viner, R. (2005). Adolescent development. Bmj, 330(7486), 301-304.

[10] Gouda, Gururaj Ganapati, \& D'Mello, Laveena (2019). A Study on the Teacher-Student Relationship and its Impact on the Behaviour of High School Students. International Journal of Case Studies in Business, IT, and Education (IJCSBE), 3(1), 28-34.

[11] Gilbert, J. (2007). Risking a relation: Sex education and adolescent development. Sex Education, $7(1), 47-61$.

[12] Indranil Manna (2014). Growth Development and Maturity in Children and Adolescent: Relation to Sports and Physical Activity. American Journal of Sports Science and Medicine, 2(5), 48-50.

[13] William Damon \& Richard M. Lerner (2008). Child and Adolescent Development; An Advanced Course (1 $1^{\text {st }}$ edi). John Wiley \& Sons, Inc, pp-141-171.

[14] Collins, W. A. (2003). More than myth: The developmental significance of romantic relationships during adolescence. Journal of research on adolescence, 13(1), 1-24.

[15] David Moshman (2005). Adolescent Psychological Development Rationality, Morality and Identity ( ${ }^{\text {nd }}$ edi). Lawrence Erlbaum Associates, Publishers, pp-17-33.

[16] Von Stumm, S., Hell, B., \& Chamorro-Premuzic, T. (2011). The hungry mind: Intellectual curiosity is the third pillar of academic performance. Perspectives on Psychological Science, 6(6), 574-588.

[17] Tiwari, G., \& Galundia, R. (2016). Academic backwardness among rural adolescents: Challenge for society. International Journal, 4(3), 438-443.

[18] Schmidt, J., \& Lockwood, B. (2017). Love and other grades: A study of the effects of romantic relationship status on the academic performance of university students. Journal of College Student Retention: Research, Theory \& Practice, 19(1), 81-97. 
[19] Beniwal, R. P., Sachdev, A., Kumar, V., Bhojak, M. M. \& Tambi, A. (2018). Scholastic backwardness among school students: Prevalence and correlates. Telangana Journal of Psychiatry, 4(1),11-15

[20] Savioja, H. (2019). Sexual behavior in adolescence: The role of depression, delinquency, and family-related factors [Ph.D Thesis, Tampere University].Google Scholar. https://trepo.tuni.fi/bitstream/handle/10024/105448/978-952-03-1018-9.pdf?sequence=1

[21] O'Brien, S. F., \&Bierman, K. L. (1988). Conceptions and perceived influence of peer groups: Interviews with preadolescents and adolescents. Child development, 59(5),1360-1365.

[22] Lardén, M., Melin, L., Holst, U., \& Långström, N. (2006). Moral judgement, cognitive distortions and empathy in incarcerated delinquent and community control adolescents. Psychology, Crime \& Law, 12(5), 453-462.

[23] Benson, P. L., Leffert, N., Scales, P. C., \& Blyth, D. A. (1998). Beyond the village rhetoric: Creating healthy communities for children and adolescents. Applied developmental science, 2(3), 138-159.

[24] Wentzel, K. R. (2002). Are effective teachers like good parents? Teaching styles and student adjustment in early adolescence. Child development, 73(1), 287-301.

[25] Tilga, H., Hein, V., Koka, A., Hamilton, K., \& Hagger, M. S. (2019). The role of teachers' controlling behaviour in physical education on adolescents' health-related quality of life: Test of a conditional process model. Educational Psychology, 39(7), 862-880.

[26] Connolly, J., Craig, W., Goldberg, A., \& Pepler, D. (1999). Conceptions of cross-sex friendships and romantic relationships in early adolescence. Journal of youth and adolescence, 28(4), 481494.

[27] Kavita Bhupta Ghosh (2014, August 27). Let's talk about what Infatuation is and ways to deal with this biggest challenge in adolescents. Kavitalistens. https://kavitalistens.wordpress.com/2014/08/27/lets-talk-about-what-infatuation-is-and-ways-todeal-with-this-biggest-challenge-in-adolescents/

[28] Roy Abraham Kallivayalil, \& Soumya P. Thomas (2019, July 4). Teenage Love May be Driven by Desire, Infatuation and Lust Not Love. Pallikkutam. https://www.pallikkutam.com/blog/teenagelove-may-be-driven-by-desire-infatuation-and-lust-not-love

[29] Connolly, J., Craig, W., Goldberg, A. \& Pepler, D. (1999). Conceptions of cross-sex friendships and romantic relationships in early adolescence. Journal of youth and adolescence, 28(4), 481494.

[30] Fleck, C. M. (2014). Adolescent Perceptions of" Healthy" Dating Relationships: Implications for Programming [Ph.D. Thesis, The College at Brockport: State University of New York]https://digitalcommons.brockport.edu/cgi/viewcontent.cgi?article $=1161 \&$ context $=$ edc thes $\underline{\text { es }}$

[31] Janardhana, N. \& Manjula, B. (2018). Infatuation and love of an adolescent girl: Dynamics of parent child relationship. Indian Journal of Child Health, 5(2), 99-103.

[32] Ševčíková, A. \& Daneback, K. (2014). Online pornography use in adolescence: Age and gender differences. European Journal of Developmental Psychology, 11(6), 674-686.

[33] Miranda, D. M., Costa, D., Costa, D. D. S., Malloy-Diniz, L. F., Romano-Silva, M. A. \& de Paula, J. J. (2019). Investigation on the Attention Deficit Hyperactivity Disorder effect on infantuation and impulsivity in adolescents. Frontiers in behavioral neuroscience, 13(137), 1-7.

[34] Rogers, A. A., Ha, T., Updegraff, K. A. \& Iida, M. (2018). Adolescents' daily romantic experiences and negative mood: A dyadic, intensive longitudinal study. Journal of youth and adolescence, 47(7), 1517-1530. 
[35] Price, M., Hides, L., Cockshaw, W., Staneva, A. A. \& Stoyanov, S. R. (2016). Young love: Romantic concerns and associated mental health issues among adolescent help-seekers. Behavioral Sciences, 6(2), 1-14.

[36] Berglund, H. \& Wennberg, K. (2006). Creativity among entrepreneurship students: comparing engineering and business education. International Journal of Continuing Engineering Education and Life Long Learning, 16(5), 366-379.

[37] Shulman, S., \& Kipnis, O. (2001). Adolescent romantic relationships: A look from the future. Journal of Adolescence, 24(3), 337-351.

[38] Li, X., Huang, C. Y. S. \& Shen, A. C. T. (2019). Romantic involvement and adolescents' academic and psychosocial functioning in Chinese societies. Children and Youth Services Review, 96(1), 108-117.

[39] Rueda, H. A., Lindsay, M. \& Williams, L. R. (2015). "She posted it on Facebook" Mexican American adolescents' experiences with technology and romantic relationship conflict. Journal of Adolescent Research, 30(4), 419-445.

[40] Sandhya Varma (2018, April 17). How to talk to your teenage child about love and infatuation. Mathrubhumi. https://english.mathrubhumi.com/news/columns/parenting/how-to-talk-to-yourteenage-child-about-love-and-infatuation-parenting-tips-sandhya-varma-teenage-love-1.2747326

[41] Varma, P., \& Mathur, A. (2015). Adolescent romantic relationships. The International Journal of Indian Psychology, 3(1), 15-27.

[42] Bouchey, H. A. \& Harter, S. (2005). Reflected appraisals, academic self-perceptions, and math/science performance during early adolescence. Journal of educational psychology, 97(4), 673-686.

[43] George, J. N., Amaresh, A. \& Rampriyanka, S. (2014). Scholastic underachievement in adolescents: a comparative study in government and private schools and Jr. Colleges. Journal of Evolution of Medical and Dental Sciences, 3(17), 4548-4556. 